\title{
CARACTERIZAÇÃO E DIVERGÊNCIA GENÉTICA DE GENÓTIPOS DE MILHO COM POTENCIAL FORRAGEIRO AVALIADOS EM REGIÃO SEMIÁRIDA
}

\author{
Maisa Nascimento Carvalho' ${ }^{1}$, Eduarda Santos Silveira ${ }^{2}$, Breno dos Santos Menezes ${ }^{3}$, Tâmara \\ Rebecca Albuquerque de Oliveira ${ }^{4}$, Gustavo Hugo Ferreira de Oliveira ${ }^{5}$
}

\section{RESUMO}

A produção de milho para consumo animal segue duas aptidões em relação à produção de ração em regiões semiáridas: grãos e silagem. No entanto, o alto sertão Sergipano, região comumente com baixa disponibilidade hídrica, apresenta escassez de alimentos. Desta forma, a obtenção de variabilidade genética, oriunda de cruzamentos específicos, podem auxiliar na seleção de genótipos de milho com potencial forrageiro. Objetivou-se caracterizar genótipos comerciais e experimentais de milho para obtenção de blocos de cruzamentos com potencial forrageiro avaliados em região semiárida. O experimento foi realizado na Fazenda Experimental da Embrapa - Semiárido, em delineamento em blocos incompletos em látice quadrado reticulado $6 \times 6$, com duas repetições, totalizando36 tratamentos. Analisou-se as variáveis altura de planta, diâmetro do colmo, peso de parcela, massa fresca, massa seca e massa de forragem. Os dados foram submetidos a análise de correlação fenotípica, contribuição relativa de cada variável e divergência genética. Indicou-se a formação de pelo menos três blocos de cruzamentos: bloco I, com aptidão para massa fresca; bloco II, com aptidão de peso de parcela e massa de forragem; bloco III, para aptidão de altura de planta, diâmetro do colmo e massa seca.

Palavras-chave: Blocos de Cruzamentos, Silagem, Melhoramento de Plantas, Sustentabilidade, Zea mays

\section{CHARACTERIZATION AND GENETIC DIVERGENCE OF MAIZE GENOTYPES WITH FORAGE POTENTIAL EVALUATED IN SEMI-ARID REGION}

\begin{abstract}
The production of maize to feed animals follows two aptitudes in relation to production of feed in semiarid regions: grains and silage. However, the high Sergipano sertão is a region commonly with low water availability and food shortages. Thus, obtaining genetic variability from specific crosses can assist in the selection of maize genotypes with forage potential. The objective was to characterize commercial and

\footnotetext{
${ }^{1}$ Eng. Agrônoma, Mestranda em Agronomia (Genética e Melhoramento de Plantas) UNESP/ Faculdade de Ciências Agrárias e Veterinárias; Jaboticabal - SP; maisa.carvalho@unesp.br

2 Graduanda em Agronomia, Universidade Federal de Sergipe/ Campus do Sertão, Nossa Senhora da Glória - SE; silveira12eduarda@gmail.com;

3 Eng. Agrônomo, Universidade Federal de Sergipe Campus do Sertão, Nossa Senhora da Glória - SE; brenomenezes480@gmail.com;

${ }^{4}$ Eng. Agrônoma, Doutora em Genética e Melhoramento de Plantas, Universidade Estadual do Norte Fluminense Darcy Ribeiro; Campos dos Goytacazes - RJ ; tamara_rebecca@hotmail.com;

${ }^{5}$ Eng. Agrônomo, Doutor em Agronomia (Genética e Melhoramento de Plantas), Universidade Federal de Sergipe/ Campus do Sertão, Nossa Senhora da Glória - SE; gustavo.ufs@ufs.br.
} 
ISSN 2525-4804

experimental maize genotypes to obtain crossing blocks with forage potential evaluated in semi-arid region. The experiment was carried out at the Embrapa Experimental Farm - Semi-arid, the square latice lattice design was made in incomplete block structure with dimension 6x6 with two replications and 36 treatments. The variables plant height, stem diameter, plot weight, fresh mass, dry mass and forage mass were analyzed. The data were submitted to phenotypic correlation analysis, relative contribution of each variable and genetic divergence. There were indications of the formation of at least three intersection blocks: block I, suitable for fresh mass; block II, with suitability of parcel weight and forage mass; block III, suitable for plant height, stem diameter and dry mass.

Keywords: Intersection Blocks, Silage, Plant Breeding, Sustainability, Zea mays. 


\section{INTRODUÇÃO}

No Brasil, há aproximadamente quatro milhões de hectares destinados ao plantio de milho (Zea mays L.) para fins de silagem (CONAB, 2018). $\mathrm{O}$ uso intensivo da silagem é devido as suas características favoráveis, tais como: alta produção de massa seca por unidade de área, facilidade de colheita mecânica, excelente qualidade de fermentação, manutenção do valor nutritivo da massa ensilada e o baixo teor de fibra em detergente neutro (FDN) (Carvalho et al., 2015). Marquardt et al. (2017), analisando a composição bromatológica da silagem de milho, apresentou valor médio de $319 \mathrm{~g}$ de MS kg ${ }^{1}$ de matéria natural, assim como a proteína bruta de $78,8 \mathrm{~g} \mathrm{~kg}^{-1}$ de $\mathrm{MS}$ e as concentrações de FDN variaram de 537 e $517 \mathrm{~g} \mathrm{~kg}^{-1}$ de MS.

A silagem de milho é utilizada, principalmente, na dieta das vacas leiteiras, sendo as regiões sul e sudeste do Brasil as que mais produzem silagem de milho (Pereira, 2013). No Nordeste, os estados que apresentaram maior produção de leite em 2017 foram Bahia (870 milhões de litros), seguido pelo Pernambuco (796 milhões de litros) e Ceará (578 milhões de litros), sendo que o estado de Sergipe ficou em quinto lugar com uma produção de 338 milhões de litros de leite (Zoccal, 2019).

O fornecimento da forragem, na forma de silagem, é uma alternativa eficaz na solução de problemas de escassez de alimento no período seco para o rebanho nacional. Assim, a silagem fornecida aos animais no período de estiagem, permite que o rebanho entre no período chuvoso com boa massa corporal (Fernandes et al., 2016). Essa opção é frequentemente utilizada em regiões de clima semiárido, porém, são regiões que apresentam condições de irregularidade de chuvas, o que impactam profundamente a produtividade $\mathrm{e}$ qualidade das silagens obtidas (Dunière et al., 2013). $\mathrm{O}$ uso de genótipos melhorados de milho, mais produtivos e adaptados às condições do ambiente, tem sido apontado como responsável pelas silagens de melhor qualidade e, consequentemente, maior produção animal (Melo et al., 2018).
Diante da ausência de programas de melhoramento com finalidade de obtenção de melhores genótipos de milho, com aptidão forrageira no semiárido, propõem-se, portanto, por sua importância, a obtenção de blocos de cruzamentos entre genitores com potencial forrageiro que explorem o fenômeno de heterose nos cruzamentos formados em prol da melhoria da qualidade produtiva de forragem nessa região.

Nesse contexto, a análise de divergência genética permite avaliar e agrupar genótipos, caracterizando-se pela transformação de um grupo heterogêneo, em dois ou mais grupos homogêneos em contexto multivariado. Assim, proporcionar-se-á cruzamentos entre materiais contrastantes e ganhos com a seleção (Alves et al., 2015). Este tipo de análise tem grande importância visando a hibridização, pois a seleção de pais divergentes aumenta o efeito heterótico, obtendo assim progênies superiores (Santos et al., 2020). Para a predição da divergência pode ser usado os métodos de análise multivariada, como componentes principais, variáveis canônicas e métodos aglomerativos (Nardino et al., 2017).

Diante do exposto, objetivou-se caracterizar genótipos comerciais e experimentais de milho para obtenção de blocos de cruzamentos com potencial forrageiro avaliados em região semiárida.

\section{MATERIAL E MÉTODOS}

O experimento foi realizado na safra 2018, na Fazenda experimental da Embrapa - Semiárido no município de Graccho Cardoso, Sergipe, Brasil, com latitude $10^{\circ} 12$ ' $52^{\prime}$ 'S, longitude $37^{\circ} 19^{\prime} 01$ ' W e altitude de 268 m, região do Alto Sertão Sergipano. Segundo a classificação de Köppen, o tipo climático é o BSsh' - clima muito quente tipo estepe, estação chuvosa no inverno.

O delineamento experimental utilizado foi em blocos incompletos em látice quadrado reticulado 6x6, com duas repetições e, portanto, 36 tratamentos (Tabela 1). 
Tabela 1 - Cultivar, tipo, ciclo, fase e obtentor das cultivares avaliadas no experimento, conduzido na fazenda experimental da Embrapa Semiárido, localizada no município de Graccho Cardoso - SE, no ano agrícola 2018.

\begin{tabular}{|c|c|c|c|c|}
\hline Tratamento & Tipo & Ciclo & Fase & Obtentor \\
\hline 1 & HS & $\mathrm{P} / \mathrm{N}$ & Comercial & Embrapa \\
\hline 2 & V & $\mathrm{P} / \mathrm{N}$ & Comercial & Embrapa \\
\hline 3 & $\mathrm{~V}$ & $\mathrm{P} / \mathrm{N}$ & Experimental & Embrapa \\
\hline 4 & V & $\mathrm{P} / \mathrm{N}$ & Comercial & Embrapa \\
\hline 5 & V & $\mathrm{P} / \mathrm{N}$ & Experimental & UFV \\
\hline 6 & V & $\mathrm{P} / \mathrm{N}$ & Comercial & EMPARN \\
\hline 7 & V & SP & Comercial & Embrapa \\
\hline 8 & $\mathrm{~V}$ & SP & Pré-Comercial & Embrapa \\
\hline 9 & $\mathrm{~V}$ & SP & Comercial & EMPARN \\
\hline 10 & HTC & SP & Experimental & Embrapa \\
\hline 11 & HTC & SP & Experimental & Embrapa \\
\hline 12 & HTC & $\mathrm{P} / \mathrm{N}$ & Experimental & Embrapa \\
\hline 13 & HTC & $\mathrm{P} / \mathrm{N}$ & Experimental & Embrapa \\
\hline 14 & HTC & $\mathrm{P} / \mathrm{N}$ & Experimental & Embrapa \\
\hline 15 & HTC & $\mathrm{P} / \mathrm{N}$ & Experimental & Embrapa \\
\hline 16 & HTC & $\mathrm{P} / \mathrm{N}$ & Experimental & Embrapa \\
\hline 17 & HTC & $\mathrm{P} / \mathrm{N}$ & Experimental & Embrapa \\
\hline 18 & $\mathrm{HI}$ & $\mathrm{P} / \mathrm{N}$ & Experimental & Embrapa \\
\hline 19 & $\mathrm{~V}$ & $\mathrm{P} / \mathrm{N}$ & Experimental & IAPAR \\
\hline 20 & V & $\mathrm{P} / \mathrm{N}$ & Experimental & IAPAR \\
\hline 21 & V & $\mathrm{P} / \mathrm{N}$ & Experimental & IAPAR \\
\hline 22 & $\mathrm{HI}$ & $\mathrm{P} / \mathrm{N}$ & Experimental & Embrapa \\
\hline 23 & HTC & $\mathrm{P} / \mathrm{N}$ & Experimental & Embrapa \\
\hline 24 & $\mathrm{~V}$ & SP & Experimental & Embrapa \\
\hline 25 & HT & $\mathrm{P} / \mathrm{N}$ & Comercial & Embrapa \\
\hline 26 & HTC & $\mathrm{P} / \mathrm{N}$ & Experimental & Embrapa \\
\hline 27 & V & $\mathrm{P} / \mathrm{N}$ & Experimental & Embrapa \\
\hline 28 & V & $\mathrm{P} / \mathrm{N}$ & Experimental & Embrapa \\
\hline 29 & $\mathrm{~V}$ & $\mathrm{P} / \mathrm{N}$ & Experimental & Embrapa \\
\hline 30 & $\mathrm{~V}$ & $\mathrm{P} / \mathrm{N}$ & Experimental & CATI \\
\hline 31 & $\mathrm{~V}$ & $\mathrm{P} / \mathrm{N}$ & Comercial & CATI \\
\hline 32 & HI & $\mathrm{P} / \mathrm{N}$ & Experimental & CATI \\
\hline 33 & HI & $\mathrm{P} / \mathrm{N}$ & Experimental & Embrapa \\
\hline 34 & HI & $\mathrm{P} / \mathrm{N}$ & Experimental & Embrapa \\
\hline 35 & HD & $\mathrm{P}$ & Comercial & Embrapa \\
\hline 36 & V & $\mathrm{P} / \mathrm{N}$ & Experimental & UFV \\
\hline
\end{tabular}


Cada parcela constituiu-se de duas linhas de quatro metros, espaçadas em $0,20 \mathrm{~m}$ entre plantas e $0,80 \mathrm{~m}$ entre linhas, totalizando 22 plantas por linha, com estande final estimado de 55.000 plantas por hectare. A semeadura foi realizada manualmente com uma semente por cova. Para se obter o efeito bordadura dentro da parcela foi adicionado duas sementes na primeira e última cova da linha. Na bordadura da área experimental foi usado cultivares de milho convencional, com o mesmo espaçamento adotado na parcela experimental.

A área foi preparada revolvendo o solo a 30 $\mathrm{cm}$ de profundidade, com auxílio de um arado de disco e posteriormente usado a grade niveladora. Em seguida foram feitos os sulcos de plantio na regulagem de $80 \mathrm{~cm}$ de distância entre as hastes a 10 $\mathrm{cm}$ de profundidade. Não houve suplementação com irrigação durante a condução do experimento.

De acordo com a análise de solo (Tabela 2) foi realizada a adubação de fundação, adicionando manualmente $85 \mathrm{~kg} \mathrm{ha}^{-1}$ do adubo comercial 10-3010 , em cada linha de plantio. A adubação de cobertura foi parcelada em duas vezes, sendo adicionado de forma manual $50 \mathrm{~kg} \mathrm{ha}^{-1}$ de Sulfato de Amônio em cada linha, a $5 \mathrm{~cm}$ da planta nos estádios V4 e V6.

Tabela 2 - Análise química do solo realizada pelo Laboratório de Solos da Embrapa Tabuleiro Costeiros.

\begin{tabular}{|c|c|c|c|c|c|c|c|c|}
\hline \multirow{2}{*}{$\begin{array}{c}\text { M.O. } \\
\left(\mathrm{g} \mathrm{kg}^{-1}\right)\end{array}$} & \multirow{2}{*}{$\begin{array}{c}\mathrm{pH} \\
\text { em } \\
\mathrm{H}_{2} \mathrm{O}\end{array}$} & $\mathrm{Ca}$ & Mg & $\mathbf{H}+\mathbf{A l}$ & Al & $\mathbf{P}$ & $\mathbf{K}$ & $\mathbf{N a}$ \\
\hline & & \multicolumn{4}{|c|}{$\left(\mathrm{mmol}_{\mathrm{c}} \mathrm{dm}^{-3}\right)$} & \multicolumn{3}{|c|}{$\left(\mathrm{mg} \mathrm{dm}^{-3}\right)$} \\
\hline 22,54 & 5,83 & 19,63 & 18,99 & 48,02 & 0,39 & 1,84 & 134,91 & 23,55 \\
\hline
\end{tabular}

M.O. - Matéria Orgânica; $\mathrm{Ca}$ - Cálcio; Mg - Magnésio; H+Al - Hidrogênio mais alumínio; Al - Alumínio; P - Fósforo, K - Potássio e Na - Sódio.

Em razão das várias injúrias causadas pela lagarta do cartucho [Spodoptera frugiperda (J. E., Smith, 1797)], houve aplicação do inseticida sistêmico Brilhante ${ }^{\circledR}$, após a adubação de cobertura. A área foi pulverizada com o herbicida comercial Atrazina $^{\circledR}$, do grupo químico triazina, com dose de 12,5 mLlitro $^{-1}$. A recomendação de aplicação foi realizada por meio da bula dos devidos produtos.

Por ocasião do florescimento, as parcelas foram devidamente etiquetadas, permitindo boa precisão de avaliação e identificação. As variáveis avaliadas foram: Altura planta (AP), avaliando-se a média de oito plantas presentes na parcela por meio de uma régua graduada; Diâmetro do colmo (DC), medindo-se a média do diâmetro do colmo de oito plantas dentro da parcela com o auxílio de um paquímetro; Peso da parcela (PP), todas as plantas da parcela foram cortadas, etiquetadas e pesadas em uma balança digital; Peso médio de massa fresca (MFe), todas as plantas das parcelas foram trituradas em uma forrageira e em seguida retirou-se duas amostras da parte aérea sendo pesadas em uma balança digital; Massa seca (MS), as duas amostras da MF foram acondicionada em uma estufa a $55^{\circ} \mathrm{C}$, onde ficaram por três dias, depois retiradas e pesadas novamente; Massa de forragem (MFo), medida obtida por meio da Equação 1.

$$
\begin{aligned}
M F o & =\frac{\text { Peso da amostra }(g) * I M S}{\text { Área amostral }} * 10 \quad \text { (Equação 1) } \\
& \text { Onde: } \\
& \text { MFo - Massa de Forragem; } \\
& \text { IMS - Índice de massa seca (MS/MF); }
\end{aligned}
$$

Os dados de cada variável foram submetidos a análise de variância em látice com recuperação da informação interblocos. As obtenções das medidas de dissimilaridade foram realizadas por meio da distância generalizada de Mahalanobis (1936). Para se estimar a contribuição de cada variável para 
observação da dissimilaridade foi utilizado o critério de Singh (1981). Além disso, foram estimados o coeficiente de determinação e correlação fenotípica de todas as variáveis. Os procedimentos estatísticos foram processados por meio do aplicativo computacional em genética e estatística, GENES (Cruz, 2013).

Para se realizar a análise de agrupamento foi obtida a estimativa do coeficiente de correlação cofenética como ferramenta para escolha do melhor método de agrupamento (Sokal e Rohlf, 1962). A partir da matriz de similaridade, obteve-se a matriz de dissimilaridade, na qual alocou-se os acessos em grupos de modo hierárquico pela ligação média entre grupo (Unweighted Pair Group Method with Arithmetic Mean - UPGMA), verificando-se o coeficiente de correlação cofenética (Streck et al., 2017).

A análise de UPGMA foi realizada por meio do software R Foundation (2017). O corte no dendrograma foi realizado por meio da análise "cutree", que leva em consideração a variância mínima para formação dos grupos (Reis, 2014). Por meio do agrupamento dos genótipos foi calculada as médias de cada grupo e assim determinado a aptidão destes. Foi utilizado o software Tableau 2020.1 para obtenção de gráficos e figuras.

\section{RESULTADOS}

Observou-se diferença significativa entre os genótipos para todas as variáveis, demonstrando que pelo menos um genótipo é diferente dos demais, podendo-se selecionar genótipos superiores em relação a variável estudada (Tabela 3). Os coeficientes de variação apresentaram-se nos limites entre 7,38 a 18,26 para diâmetro do colmo (DC) e peso médio de massa fresca (MF), respectivamente.

Tabela 3 - Análise de variância com os tratamentos ajustados com recuperação da informação interblocos, os coeficientes de variação, médias fenotípicas, coeficiente de determinação, variâncias genotípicas, ambientais e fenotípicas avaliadas na fazenda experimental da Embrapa - Semiárido.

\begin{tabular}{|c|c|c|c|c|c|c|c|}
\hline \multirow{2}{*}{ FV } & \multirow{2}{*}{ GL } & \multicolumn{6}{|c|}{ QM } \\
\hline & & $\mathbf{A P}$ & DC & PP & MF & MS & MFO \\
\hline Trat (Ajust.) & 35 & $108,62 *$ & $0,03^{*}$ & $0,34^{*}$ & $0,0057 * *$ & $0,00039 *$ & $28408,90 * *$ \\
\hline $\begin{array}{l}\text { Resíduo } \\
\text { Intrabl. }\end{array}$ & 25 & 23,99 & 0,02 & 0,29 & 0,0067 & 0,00037 & 34350,18 \\
\hline Fator de ajuste & & 0,12 & 0,74 & 0,048 & 0,06 & 0,06 & 0,02 \\
\hline CV $(\%)$ & & 9,42 & 7,38 & 16,08 & 18,26 & 13,86 & 17,07 \\
\hline Média & & 51,96 & 1,72 & 3,34 & 0,44 & 0,13 & 1085,44 \\
\hline $\mathrm{R}^{2}$ & & $>0,0$ & 0,55 & 0,34 & 0,42 & $>0,0$ & 0,58 \\
\hline$\delta^{2} \mathrm{G}$ & & $>0,0$ & 0,0008 & 0,073 & 0,00001 & $>0,0$ & 1019,56 \\
\hline$\delta^{2} \mathrm{~A}$ & & 44,65 & 0,138 & 0,139 & 0,00022 & 0,0047 & 16376,28 \\
\hline$\delta^{2} \mathrm{~F}$ & & 39,18 & 0,146 & 0,212 & 0,00023 & 0,0026 & 0,00513 \\
\hline
\end{tabular}

$*^{*} \mathrm{e}^{* *}$, significa, significativo a $1 \%$ e a $5 \%$ de probabilidade, respectivamente, pelo teste F. AP: Altura da Planta, DC: Diâmetro do colmo, PP: Peso de parcela (kg), MFe: Massa Fresca (kg), MS: Massa Seca (kg), PMS: Porcentagem de Massa Seca e MFo: Massa de Forragem (kg MS/ha); $\mathrm{R}^{2}$ : coeficiente de determinação; $\delta^{2} \mathrm{G}$ : Variância genotípica; $\delta^{2} \mathrm{~A}$ : Variância ambiental; $\delta^{2} \mathrm{~F}$ : Variância fenotípica. 
Observou-se que o diâmetro do colmo e massa de forragem (MFo) apresentaram coeficiente de determinação acima de $50 \%$, sendo as mais relevantes com relação a magnitude. Das variâncias apresentadas, observou-se maiores magnitudes das variâncias fenotípicas em relação a genotípica (Tabela 3).

Os híbridos comerciais, usados no experimento, apresentaram pouca variabilidade para todas as variáveis analisadas. Diferente destes, as cultivares experimentais, os híbridos intervarietais (HI), híbridos topcross (HTC) e as variedades apresentaram ampla variabilidade para todas as variáveis estudadas, como por exemplo, as variedades comerciais, que exibiram altura de planta variando de $40 \mathrm{~cm} \mathrm{a}>60 \mathrm{~cm}$. (Figura 1).

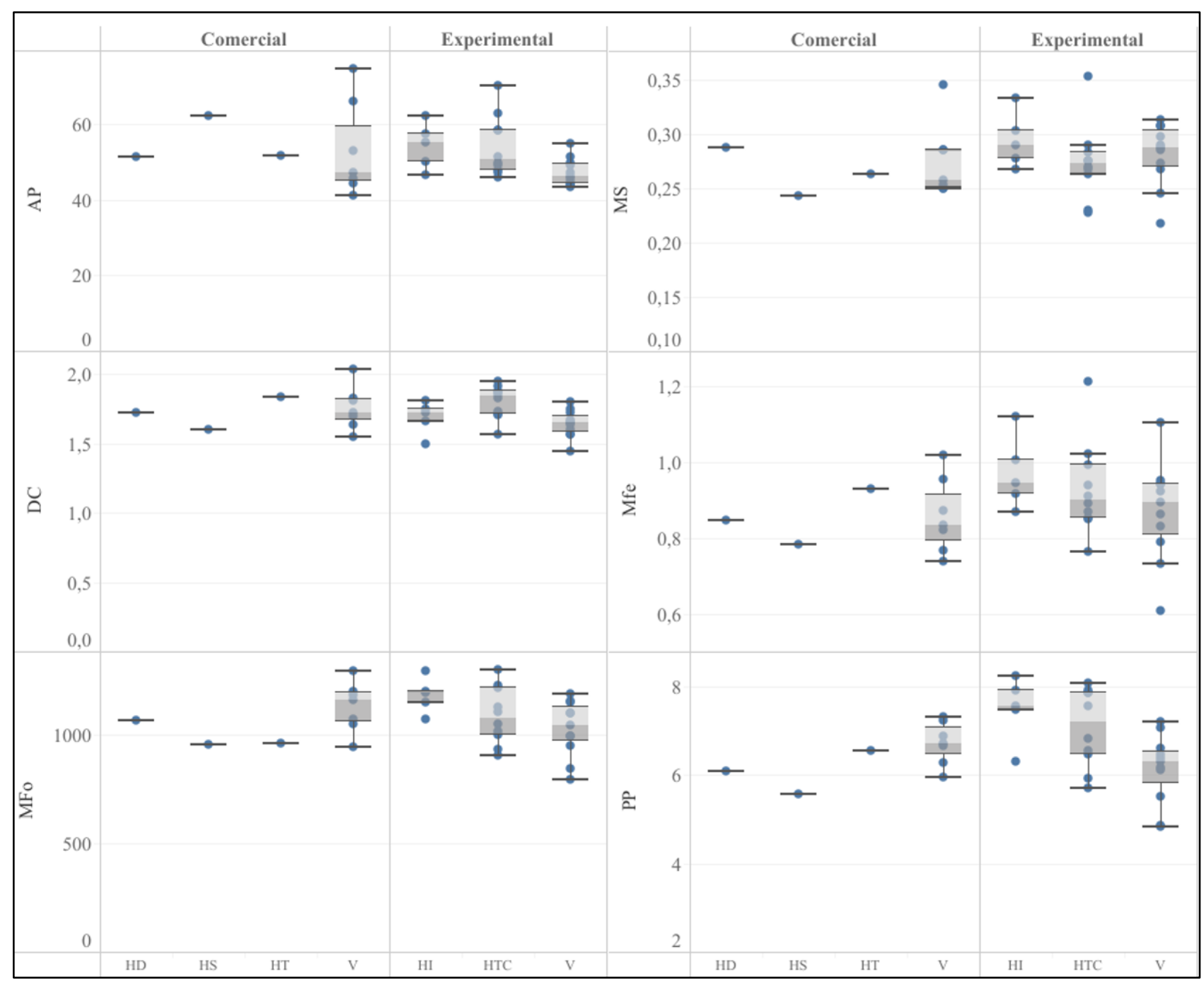

Figura 1. Boxplot das classes genéticas de híbrido duplo (HD), híbrido simples (HS), híbrido triplo (HT), variedade (V), híbrido intervarietal (HI) e híbrido topcross (HTC), para as variáveis altura de planta (AP), diâmetro do colmo (DC), massa de forragem (MFo), massa seca (MS), massa fresca (Mfe) e peso de planta (PP). 
Os dados apresentaram-se dentro da média e mediana e sem outlier, com exceção do HTC experimental nas variáveis MS e MFe. Isso possibilitou confiabilidade nos dados apresentados para este estudo.

As tendências de correlação entre as variáveis podem ser observadas a partir da distribuição dos pontos. Sendo assim, os pontos que se agruparem a fim de formar uma linha perpendicular, mostram a tendência a correlação entre as variáveis. Observa-se na Figura 2 a distribuição dos pontos, e a formação da linha perpendicular entre as variáveis MS e MFe, bem como nas variáveis PP e MFo. Foram observadas também variáveis que não apresentaram nenhuma tendência, ou seja, os dados estavam dispersos, variáveis como MS e AP, MS e PP, MS e DC, MFe e MFo, não apresentaram tendência a correlação.

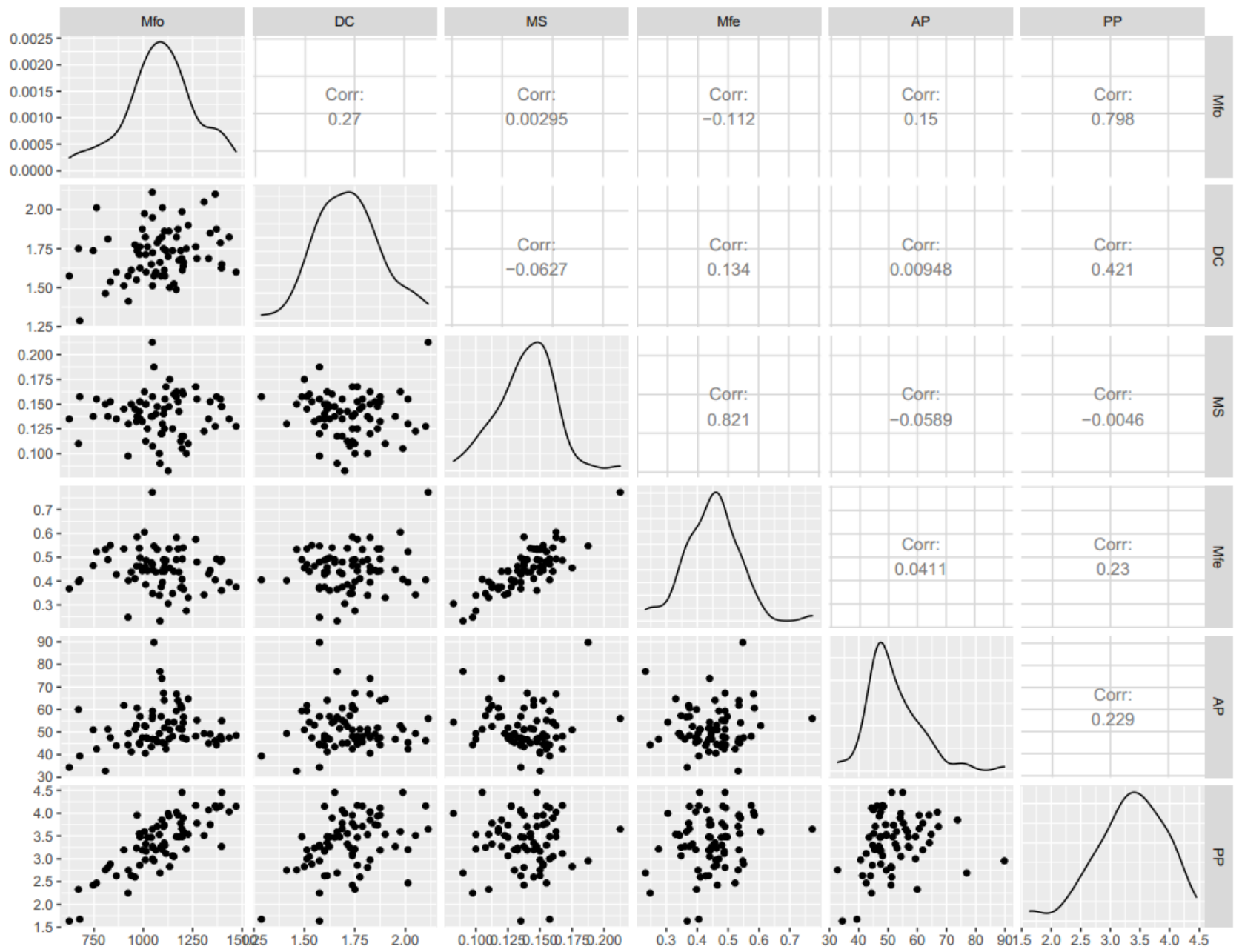

Figura 2. Coeficiente de correlação de Pearson para variáveis morfológicas avaliadas em 36 genótipos de milho.

As correlações entre as características avaliadas auxiliam no programa de melhoramento para inferir sobre uma possível seleção indireta. $\mathrm{Na}$ correlação fenotípica, as variáveis peso de parcela e massa de forragem apresentaram a maior correlação entre todas variáveis $(0,86)$. A variável peso de parcela e diâmetro do colmo apresentaram correlação de 0,55 e a correlação do diâmetro do colmo com a massa de forragem foi de 0,47 . Outras variáveis que apresentaram correlação positiva foram AP e DC, AP e PP, DC e MF, PP e MF, MS e MF, AP e MFo, MF e MFo. Consequentemente, as variáveis que se correlacionaram negativamente foram AP e MS; DC e MS; PP e MS; AP e MF; MS e MFo. 
As variáveis que contribuíram para observar a dissimilaridade genética foram: peso de parcela (2098,72 com 41,15\%), massa seca $(1505,14$ com $29,51 \%)$, diâmetro do colmo (779,93 com 15,29\%) e altura de planta (673,23 com 13,20\%) (Tabela 4).

Já variáveis como massa de forragem $(-109,56$ com $-2,14 \%)$ e massa fresca $(-386,88$ com $-7,58 \%)$ não auxiliaram na observação da divergência genética dos genótipos estudados.

O estudo da relação das características altura de planta, diâmetro do colmo, peso de parcela, massa seca, massa fresca e massa de forragem, usando a distâncias generalizada de Mahalanobis $\left(\mathrm{D}^{2}\right)$, são apresentadas na Figura 3.

Foram formados três grupos, de acordo com a similaridade entre os genótipos. O grupo I reuniu os genótipos 29 e 36, o grupo II alocou os genótipos 4, $7,8,9,10,13,15,18,20,21,22$ e 27 e o grupo III dispôs os genótipos $1,2,3,5,6,11,12,14,16,17$, $23,26,28$ e 33 .

Os genótipos apresentaram maior similaridade para massa fresca, no grupo I, para peso de parcela e massa de forragem, grupo II e para altura de planta, diâmetro do colmo e massa seca, grupo III (Tabela 5).

Tabela 4 - Contribuição relativa das variáveis estudadas em relação aos 36 genótipos, pelo método proposto por Singh (1981).

\begin{tabular}{ccc}
\hline Variável & Singh & Valor (\%) \\
\hline Altura de Planta & 673,23 & 13,20 \\
Diâmetro do Colmo & 779,93 & 15,29 \\
Peso de Parcela & 2098,72 & 41,15 \\
Massa Fresca & $-386,88$ & $-7,58$ \\
Massa Seca & 1505,14 & 29,51 \\
Massa de forragem & $-109,56$ & $-2,14$ \\
\hline
\end{tabular}

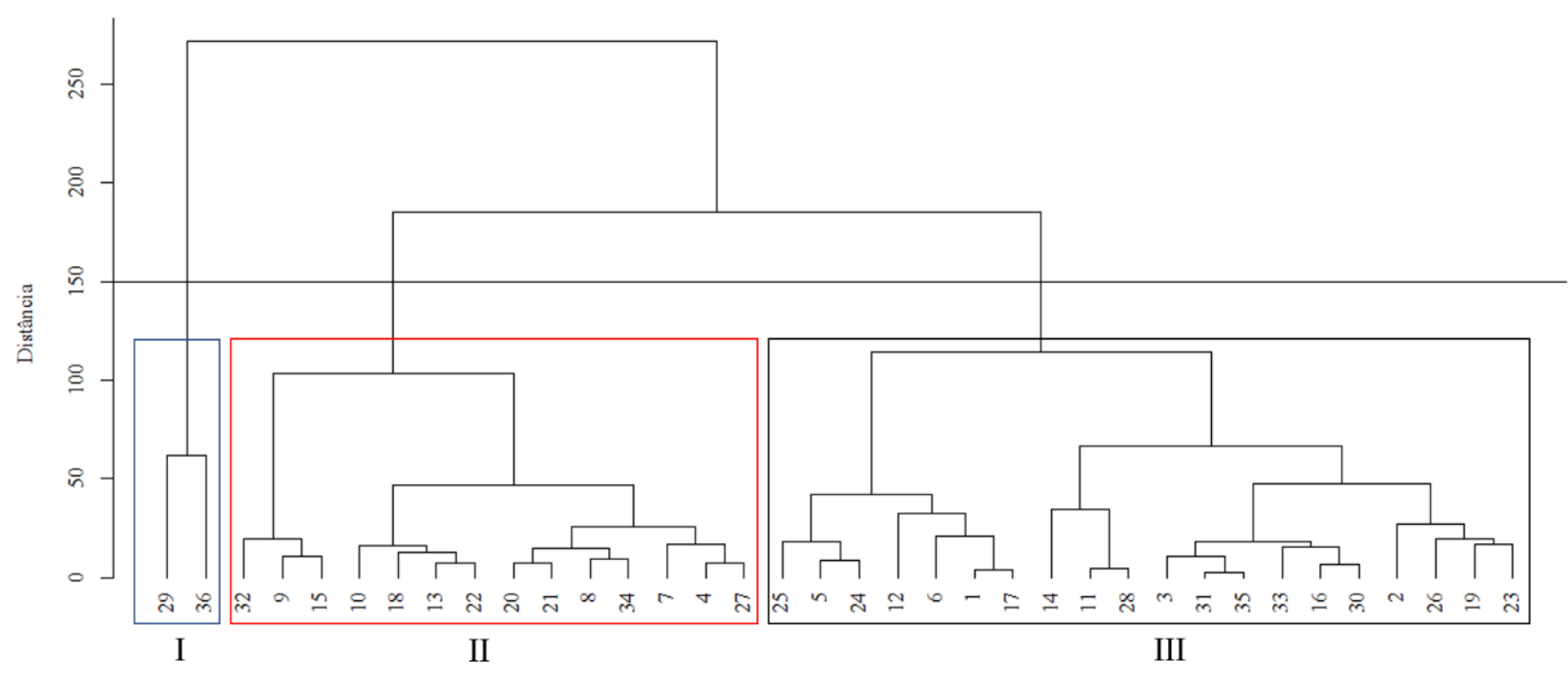

Figura 3 - Dendrograma representativo da dissimilaridade genética dos 36 genótipos de milho em relação as variáveis, Altura da Planta, Diâmetro do colmo, Peso de parcela ( $\mathrm{kg})$, Massa Fresca (kg), Massa Seca $(\mathrm{kg})$ e Massa de Forragem ( $\left.\mathrm{kg} \mathrm{MS} \mathrm{ha}{ }^{-1}\right)$ pelo método vizinho mais próximo utilizando a distância generalizada de Mahalanobis $\left(\mathrm{D}^{2}\right)$. 
Tabela 5 - Média dos grupos I, II e III para as variáveis Altura da Planta, Diâmetro do colmo, Peso de parcela $(\mathrm{kg})$, Massa Fresca (kg), Massa Seca (kg) e Massa de Forragem (kg MS ha-1)

\begin{tabular}{ccccccc}
\hline & AP & DC & PP & MFe & MS & MFo \\
\hline Grupo I & 43,59 & 1,55 & 2,43 & 0,144 & 0,43 & 821 \\
Grupo II & 53,58 & 1,76 & 3,54 & 0,132 & 0,42 & 1177,59 \\
Grupo III & 54,39 & 1,79 & 3,51 & 0,139 & 0,46 & 1103,18 \\
\hline
\end{tabular}

AP: altura de planta; DC: diâmetro do colmo; MFo: massa de forragem; MS: massa seca; MFe: massa fresca; PP: peso de planta.

\section{DISCUSSÃO}

Os coeficientes de variação (CV) estão dentro dos limites estabelecidos na literatura, apontando a acurácia do experimento e precisão na estimativa das médias (Fritsche-Neto et al., 2017). Todas as variáveis analisadas foram significativas, demonstrando que pelo menos um genótipo foi superior na estimativa da média.

Observou-se no presente estudo a constatação de média geral abaixo da encontrada na literatura (Neumann et al., 2017; Ferreira et al., 2017), pois a caracterização dos genótipos ocorreu sob estresse natural da região semiárida. Além disso, houve um baixo índice pluviométrico na safra, com alto estresse observado nas parcelas, o que consequentemente atenuou maior interferência ambiental sobre os genótipos. Ainda assim, com as condições adversas, foi possível selecionar os genótipos que mais se destacaram nestas condições.

Os híbridos simples, triplos e duplos não apresentaram variação para todas as variáveis, devido a formação de dois, três e quatro genitores, respectivamente. Diferente das classes como as variedades, híbridos intervariatais e híbrido topcross, que demonstra uma média e valores acima ou abaixo, entende-se que temos genótipos superiores e inferiores e alta variabilidade genética. A variabilidade genética é essencial nos programas de melhoramento de plantas, pois permite a heterose, possibilitando a obtenção de diferentes fenótipos e auxiliando na busca de genes com tolerância a déficit hídrico, por apresentarem alta capacidade de adaptação a ambientes específicos (Paterniani et al., 2019).

Os estudos da correlação entre variáveis auxiliam uma possível seleção indireta, sendo útil em programas de melhoramento por obter ganho de seleção em caracteres de difícil estimação (Silva et al., 2020). A correlação alta entre peso de parcela e diâmetro do colmo também foi apresentada por Beleze et al. (2003). Infere-se que, quanto maior os componentes estruturais da planta, maior será a produção de massa de forragem (Beleze et al., 2003), corroborando com o resultado do peso de parcela com correlação alta $(0,798)$ com massa de forragem.

Além disso, as variáveis massa seca e massa fresca foram fortemente correlacionadas $(0,80)$. Estas variáveis são de grande importância para seleção de genótipos de milho com finalidade de obtenção de maior produtividade de silagem, auxiliando no dimensionamento do silo e no cálculo de dietas dos animais (Melo et al., 2018). Como estas variáveis são positivamente correlacionadas, considera-se que o ganho em massa fresca favorece o ganho em massa seca.

Além da correlação, a estimativa do coeficiente de determinação das variáveis permite observar a evidência de estimativas baixas, inferindo numa possível ação não aditiva dos genes envolvidos na expressão das características, o que pode dificultar os ganhos com a seleção, mesmo indiretamente. Sabe-se que a expressão gênica depende, também, da influência do ambiente e nesse caso, estudos em situações de estresse, principalmente estresse por deficiência hídrica, comumente ocorridos em regiões 
semiáridas, devem ser mais explorados, pois o coeficiente de determinação é uma propriedade da população em estudo sendo, portanto, mutável (Cargnelutti Filho; Storck, 2009). Assim sendo, o uso das correlações sempre deve ser explorado com o auxílio das estimativas do coeficiente de determinação, visando melhores resultados em situações de avaliação em ambientes com estresse extremo.

Diante do exposto, o diâmetro do colmo e a massa de forragem (MFo) se destacam por apresentarem correlação positiva e coeficiente de determinação acima de 50\%, sendo as mais relevantes em relação à magnitude.

A contribuição relativa dos caracteres auxilia os melhoristas sobre a viabilidade das variáveis no estudo de divergência genética para possível seleção de características de maior importância (Silva, 2018). Assim, o peso de parcela e massa seca são variáveis de extrema importância para este estudo, pois seus atributos aumentam a produção de silagem e devido a sua contribuição na observação da divergência servem para auxiliar na escolha dos genitores para o programa de melhoramento (Melo et al., 2019).

Para fins de hibridação, os genótipos com maior distância genética e que se complementam são os recomendados para os programas de melhoramento, pois podem gerar variabilidade que é essencial para seleção de progênies superiores. No entanto, além da dissimilaridade, deve-se observar a média da produtividade dos genótipos, a fim de se obter maior heterose (Melo et al., 2019). Se a condição ideal de média elevada e de alta dissimilaridade não for encontrada, é possível optar por genótipos com dissimilaridade intermediária e de alta produtividade (Hauller et al., 2010).

O cruzamento de indivíduos geneticamente distantes gera maior heterozigose passível de seleção de genótipos superiores. Por isso é necessário conhecer a divergência genética dos genitores a fim de se obter maior ganho com a seleção em possíveis cruzamentos. Nesse contexto, indica-se o cruzamento dialélico parcial entre o bloco II, com aptidão de peso de parcela e massa de forragem, e o bloco III, com aptidão para altura de planta, diâmetro do colmo e massa seca.

Além disso, um dialelo parcial entre o bloco I e bloco III permite a obtenção de progênies com alta variabilidade para seleção de indivíduos com potencial para produção de forragem. Estes blocos apresentam genótipos comerciais e experimentais que são importantes para o sucesso na seleção e melhoria das características já estabelecidas no mercado.

\section{CONCLUSÕES}

Indica-se a formação de pelo menos três blocos de cruzamentos: bloco I, com aptidão para massa fresca; bloco II, com aptidão de peso de parcela e massa de forragem; bloco III, para aptidão de altura de planta, diâmetro do colmo e massa seca.

\section{AGRADECIMENTOS}

A Universidade Federal de Sergipe, Campus do Sertão pela concessão da bolsa de iniciação científica. Ao Grupo de Estudos em Melhoramento Vegetal do Semiárido - GEMS pelo auxílio na avaliação do experimento a campo e a Embrapa Milho e Sorgo e Embrapa - Semiárido pelo fornecimento das sementes e disponibilidade da área experimental, respectivamente.

\section{REFERÊNCIAS BIBLIOGRÁFICAS}

Alves, B.M.; Cargnelutti Filho, A.; Burin, C.; Toebe, M. \& Silva, L.P. (2015). Divergência genética de milho transgênico em relação à produtividade de grãos e à qualidade nutricional. Ciência Rural, 45(5), 884-891.http://dx.doi.org/10.1590/0103$8478 \mathrm{cr} 20140471$.

Beleze, J.R.F.; Zeoula, L.M.; Cecato, U.; Dian, P.H.M.; Martins, E.N. \& Falcão, A.J.D.S. (2003). Avaliação de cinco híbridos de milho (Zea mays, L.) em diferentes estádios de maturação: 1 . Produtividade, características morfológicas e correlações. Revista Brasileira de Zootecnia, 32(3), 529-537. 
Cargnelutti Filho, A., \& Storck, L. (2009). Medidas do grau de precisão experimental em ensaios de competição de cultivares de milho. Pesquisa Agropecuária Brasileira, 44(2), 111-117.

Carvalho, A.F.G.; Martin, T.N.; Santos, S.; Müller, T.M. \& Piran Filho, F.A. (2015). Perfil agronômico e bromatológico de silagem de milho no sudoeste do Paraná. Revista de la Facultad de Agronomía, 114(2), 149-159.

Conab - Companhia Nacional de Abastecimento. (2018). Acomp. safra bras. grãos - Safra 2017/18 Quinto levantamento, Brasília, 5, 1-140.

Cruz, C.D. (2013). Genes: a software package for analysis in experimental statistics and quantitative genetics. Acta Scientiarum. Agronomy, 35(3), 271276.

Dunière, L.; Sindou, J.; Chaucheyras-Durand, F.; Chevallier, I. \& Thévenot-Sergentet, D. (2013). Processamento de silagem e estratégias para evitar a persistência de microrganismos indesejáveis. Ciência e Tecnologia de Ração Animal, 182 (1-4), 1-15.

Fernandes, G.F.; Evangelista, A.F. \& Borges, L. (2016). Potencial de espécies forrageiras para produção de silagem: revisão de literatura. Revista Eletrônica Nutri Time, 13(3), 4652-4656.

Ferreira, J.P.; Andreotti, M.; Pascoaloto, I.M.; Costa, N.R.; Augusto, J.G. \& Kaneko, F.H. (2017). Espaçamento de cultivo de milho forrageiro consorciado com forrageiras tropicais para produção de silagens1. Revista Agropecuária Técnica. 38(3), 133-141.

Fritsche-Neto, R.; Vieira, R.A.; Scapim, C.A.; Miranda, G.V. \& Rezende, L.M. (2017). Updating the ranking of the coeffi cients of variation from maize experiments. Acta Scientarium, 34, 99-101. https://doi.org/10.4025/actasciagron.v34i1.13115

Hauller, A.R.; Carena, M.J. \& Miranda Filho, J. D. (2010). Quantitative genetics in maize breeding (Vol. 6). Springer Science \& Business Media.

Mahalanobis, P.C. (1936). On the generalized distance in statistics. Proceedings National Institute of Science, 12, 49-55.

Marquardt, F. I., Jobim, C. C., Bueno, A. V. I., \& Ribeiro, M. G. (2017). Altura de corte e adição de inoculante enzimo-bacteriano na composição químico-bromatológica e digestibilidade de silagens de milho avaliada em ovinos. Ciência Animal Brasileira, 18. Doi: 10.1590/1089-6891v18e-42888.

Melo, A.V. de; Santos, V.M. dos; Lopes, T.M.; Dias, M.A.R. \& Nunes, H.V. (2019). Divergência genética entre híbridos de milho em condições de deficiência hídrica. Journal of Neotropical Agriculture, 6(3), 66-75.

Melo, A.V. de; Santos, V.M. dos; Peron, A.J.; Nunes, H.V. \& Castro Tavares, R. de. (2018). Avaliação bromatológica de silagem de híbridos de milho em diferentes níveis de adubação fosfatada. Global Science and Technology, 11(2).

Nardino, M., Baretta, D., Carvalho, I. R., Follmann, D. N., Ferrari, M., Pelegrin, A. J. D., ... \& Souza, V. Q. D. (2017). Divergência genética entre genótipos de milho (Zea mays L.) em ambientes distintos. Revista de Ciências Agrárias, 40(1), 164-174.

Neumann, M.; Ghizzi, L., Heker Junior, J.C.; Carneiro, M.K.; Reinehr, L.L.; Spada, C.A. \& Maciel, G. S. (2017). Produção de forragem de milho em diferentes densidades de semeadura e épocas de colheita. Revista Brasileira de Milho e Sorgo, 16(2), 204-216.

Paterniani, M.E.A.G.Z.; Bernini, C.S.; Guimarães, P.S. \& Rodrigues, C.S. (2019). Estratégias de melhoramento para tolerância à seca em germoplasma de milho tropical. Singular Meio Ambiente e Agrárias, 1(1), 19-24.

Pereira, J.R.A. (2013). O mercado de silagem de milho no Brasil. Portal Milk Point.

R Foundation. (2017). R: the $\mathbf{R}$ project for statistical computing. Disponível em: https://www,r-project,org/. Acesso em: 07/03/2019.

Reis, R.M.; Cecon, P.R.; Puiatti, M.; Finger, F.L.; Nascimento, M.; Silva, F.F.; Carneiro, A.P.S. \& Silva, A.R. (2014). Modelos de regressão não linear aplicados a grupos de acessos de alho. Horticultura Brasileira, 32(2), 178183.http://dx.doi.org/10.1590/s0102-

05362014000200010 .

Santos, W. F., Maciel, L. C., Júnior, B. L. D., Peluzio, J. M., Sodré, L. F., Júnior, O. J. F., ... \& Barbosa, A. 
S. (2020). Genetic Divergence in Corn Genotypes for High and Low Phosphorus in Pará, Brazil. Annual Research \& Review in Biology, 82-90.

Silva, M.F.; Maciel, G.M.; Finzi, R.R.; Peixoto, J.V.M.; Rezende, W.S. \& Castoldi, R. (2020). Índices de seleção para caracteres agronômicos e químicos em população segregante de milho-doce. Horticultura Brasileira, 38(1), 71-77. Doi: 10.1590/s0102-053620200111

Silva, P.C. da. (2018). Divergência genética entre linhagens parcialmente endogâmicas de milho pipoca por métodos multivariados e redes neurais artificiais (Dissertação de Mestrado). Universidade Federal da Grande Dourados. Dourados, MS, Brasil p. 87

Singh, D. (1981). The relative importance of characters affecting genetic divergence. Indian Journal of Genetics and Plant Breeding (The), 41(2), 237-245.

Sokal, R.R. \& Rohlf, F. J. (1962). The comparison of dendrograms by objective methods. Taxon, 11(1), 3040.

Streck, E.A.; Aguiar, G.A.; Magalhães Júnior, A.M.D.; Facchinello, P.H.K. \& Oliveira, A.C.D. (2017). Variabilidade fenotípica de genótipos de arroz irrigado via análise multivariada. Revista Ciência Agronômica, 48(1), 101-109.

Valentini, L.; Shimoya, A.; Ferreira, J.M.; de Bastos Andrade, W.E.; de Oliveira, L.A.A.; de Azevedo, C.D.; Costa, C.C. da S. \& Gomes, J.M.R. (2017). Desempenho de variedades de milho em Campos dos Goytacazes-RJ. 114. ed. Niterói: PESAGRORIO.

Zoccal, R. (2019). Anuário de leite 2019 - Leite nas grandes regiões brasileiras. 102 p. Disponível em: ainfo.cnptia.embrapa.br > item , Anuario-LEITE2019. Acesso em: 22/10/2020. 